\title{
Charles L. Limoli: the study of brain irradiation is a labor of love
}

Submitted Jul 09, 2018. Accepted for publication Jul 12, 2018.

doi: $10.21037 /$ tcr.2018.07.10

View this article at: http://dx.doi.org/10.21037/tcr.2018.07.10

\section{Editor's note}

While radiation therapy is believed to be a safe and effective approach to treat a wide range of cancers, the safety of cranial radiotherapy remains contentious due to the side effects it causes such as poor memory, confusion, problems in thinking, altered mood and an overall debilitating cognitive dysfunction of patients. Over the past decade, this unresolved problem has driven many scientists' efforts to examine the impacts on cognitive performance of various brain irradiation paradigms as well as the underlying cellular mechanisms considered to be affecting these processes (1).

Charles L. Limoli (Figure 1), Professor of Radiation Oncology, University of California, Irvine, California, has been spending years studying the mechanisms in which stem cells and stem cell-derived exosomes are used to reduce injury of brain tissue and radiationinduced cognitive dysfunction, and to determine how such transplantation strategies improve cognition and ameliorate the adverse effects of radio- and chemotherapy. Taking this opportunity, TCR will be interviewing Prof. Limoli with an aim to understand the key differences between stereotactic radiosurgery and whole brain irradiation, the NIH study that he is currently working on, and his course of development in the field of radiation oncology.

\section{Expert introduction}

Charles L. Limoli, PhD, is the Professor of Radiation Oncology, University of California, Irvine (UCI), California and an editorial board member of Translational Cancer Research. After receiving his BS degree in chemistry from Massachusetts Institute of Technology (MIT), he went on to complete his $\mathrm{PhD}$ in Biomedical Sciences from University of California, San Diego (UCSD). He got his first academic appointment at University of California, San Francisco (UCSF), where he stayed for 12 years before entering UCI in 2006.

Prof. Limoli's research has focused on radiation effects in the central nervous system (CNS), where he has defined many of the mechanisms that contribute to radiationinduced cognitive dysfunction. His work has since

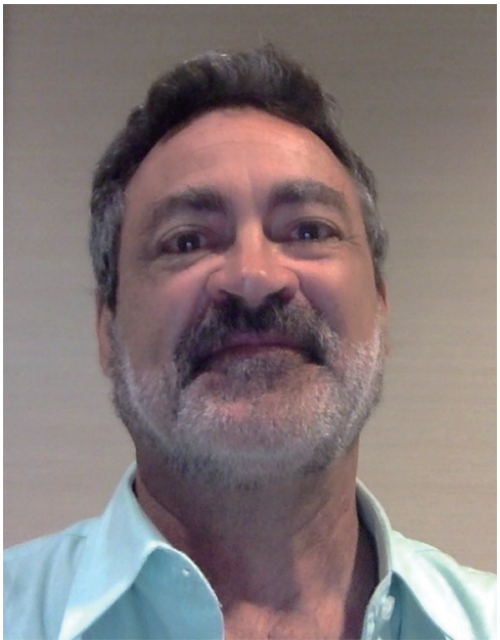

Figure 1 Prof. Charles L. Limoli.

defined the importance of oxidative stress in the brain, how irradiation disrupts neuronal structure and synaptic integrity, and how stem cells and exosomes can be used to offset the adverse effects of both radio- and chemotherapy in the brain. Continued work strives to further understand the causes, consequences and potential remedies for neurocognitive dysfunction caused by various cancer treatments.

\section{Interview}

TCR: In your previous study, you proposed the use of stereotactic radiosurgery to treat brain tumor patients. What are the advantages of this technique compared to whole brain irradiation?

Prof. Limoli: Stereotactic radiosurgery minimizes the volume of brain irradiated. In fact, the whole field of radiotherapy is going towards these stereotactic approaches which are delivering a 360-degree arc of pencil beams of radiation to come in and hit the tumor wherever it is in the brain from all possible angles that do two things. First, they try to maximize coverage of the tumor, 
but they also minimize the regions of risk, e.g., brain stem and the like. The less normal tissue you irradiated, the better off you are in terms of minimizing the side effects and complications.

\section{TCR: This study was conducted using an animal model. Has it been expanded to any clinical trials at this stage?}

Prof. Limoli: It has not yet been expanded to any clinical trials at this stage. In our clinic, people are routinely subjected to these types of radiation paradigms. They almost always get some combination of stereotactic/whole brain irradiation depending upon the distribution of lesions in the brain. Clinical trials that are currently going on are generally combining radiation and the immunotherapy and chemotherapy protocols. However, the implementation of radiation is still the forefront for stalling CNS malignancy. Chemotherapy doesn't do a whole lot. It's radiation that really stops the growth of the cancer.

\section{TCR: Would you introduce us to your NIH study "Translational strategies for protecting the brain against radio- and chemotherapy"?}

Prof. Limoli: The grant that NIH offers us is called RO1, a large grant given to an individual investigator that lasts anywhere from 3 to 5 years. For these particular projects, I have been fortunate enough to obtain two large RO1s that last for 5 years. Right now, we have over 40 scientists in my lab, and about half of them are working on these projects. Technically, we are funded to do two different things.

First, we look at the mechanisms of the current state-of-the-art treatments of radiation combined with temozolomide. Using our animal model, we implement a fractionated radiation protocol that models the current glioma treatment of 60 Gray given in single 2 Gy fractions, 5 days per week. When you put that into a biologically equivalent model, you get a biologically equivalent dose of 100 . We use three doses of 8.67 grade to model a fractionated radiotherapy protocol, and assume an alphabeta ratio of three for late neural tissue responses in the CNS. We then combine that with concurrent and follow-up chemotherapy. We give about 12 injections of temozolomide adjusted to the animal to be equivalent of what the humans get. In short, we are combining the radiation in a fractionated protocol along with the temozolomide. Following these clinically relevant treatment scenarios, animals are then subjected to a whole series of behavioral tests that interrogate hippocampal and cortical based learning in memory. In addition, we look at a whole variety of mood disorders and some of the pathology associated with these treatments.

Another aspect of these projects is to do something to fix it. Taking those same treatments, and instead of focusing on what happens in a mechanistic level, we seek to resolve some of the deleterious effects of radio- and chemotherapy using both a variety of stem cell-based approaches and an extracellular vesicle or an exosome-based approach. We can implement an intracranial or systemic injection of stem cells or stem cell-derived exosomes, and determine whether that resolves the neurocognitive complications that are associated with radiation- and chemotherapy-induced damage in the brain. What has been recently known through our work is that when we irradiate the brain, there is a big boost in neuroinflammation. One of the endpoints we use is we follow the rise of activated microglia, which are the innate immune cells residing within the bloodbrain barrier. We have shown that when we put stem cells or stem-cell derived exosomes into the brain, the neuroinflammation can be markedly attenuated. Another thing that we have now known is that if we look at principal cells or mature neurons throughout various hippocampal and cortical regions, there is a marked reduction in the structural complexity of these neurons that appears to be permanent. In other words, 12, 24 or 52 weeks after radiation and/or chemotherapy exposure, the structure of neurons, for example, the dentate granule cell neurons or principal cells within the CA1 layer of the hippocampus, the medial prefrontal cortex, the perirhinal cortex or entorhinal cortex, will undergo a remarkable reduction in dendritic complexity and spine density. Spines are the structural correlates of learning and memory that contain the synaptic machinery mediating neurotransmission. Stem cell and exosome transplantations preserve the host neuronal morphology and microvascular bed. We have shown that while radiation increases inflammation, reduces the structure of neurons and compromises the integrity of blood-brain barrier, these treatments resolve all three of these adverse indications. That's what the NIH has been funding me to look at-basically what happens to the irradiated brain and how we can fix it.

\section{TCR: What are the challenges in carrying out this study?}

Prof. Limoli: Behavioral testing takes a certain attention to detail and has to be done very carefully. Not all animals 
behave the way you want them to. They sometimes pick up cues that you might not be aware of. This makes some of the work tricky. On the other hand, chemical and biochemical analyses, structural and molecular endpoints require a wide variety of highly variable procedures to be adhered to. Structural studies looking at dendritic tracing and unbiased stereology may take several months to analyze just one region of the brain. More complete temporal and dose response studies analyzing multiple aspects of neuronal physiology can take years to complete. Therefore, doing these types of studies is a labor of love that requires both patience and persistence.

\section{TCR: Out of the variety of specialties, why are you particularly interested in radiation oncology?}

Prof. Limoli: When I was an undergraduate at MIT, I majored in chemistry and was interested in free radical chemistry, polymerization and catalysis reactions. As I was looking for jobs, I found the only type of job I could get was as an organic chemist, which wasn't that appealing. Therefore, I decided to pursue academics. I went to a lab at UCSD and was mentored by one of the leading radiation chemists in the world, John Ward. There I basically studied radiation induced free radical processes. That's how I got interested in radiation oncology and how I went from there to being a neuroscientist and stem cell biologist. Fifteen years ago, I started looking at the effects of radiation on stem cells in the brain, and this opened up a whole new field for me. I have been fortunate enough to surround myself with really talented people and we are probably the leading lab in the world looking at how radio- and chemotherapy affects the brain.

\section{TCR: As the editorial board member of TCR, do you bave} any words for our readers/peers in your field?

Prof. Limoli: Stay interested in science-it's a good way to make a difference in the world. If you have the mindset and patience for spending a few boring nights in the lab, you are working your way up in your career. It also gives you quite a bit of freedom to do what you want. If you find your passion, science gives you many opportunities to pursue.

\section{Acknowledgments}

The author would like to express his sincerest gratitude to Prof. Charles L. Limoli for sharing his insights and opinions with us.

Funding: None.

\section{Footnote}

Provenance and Peer Review: This article was commissioned by the Editorial Office, Translational Cancer Research. The article did not undergo external peer review.

Conflicts of Interest: The author has completed the ICMJE uniform disclosure form (available at http://dx.doi. org/10.21037/tcr.2018.07.10). The author has no conflicts of interest to declare.

Ethical Statement: The author is accountable for all aspects of the work in ensuring that questions related to the accuracy or integrity of any part of the work are appropriately investigated and resolved.

Open Access Statement: This is an Open Access article distributed in accordance with the Creative Commons Attribution-NonCommercial-NoDerivs 4.0 International License (CC BY-NC-ND 4.0), which permits the noncommercial replication and distribution of the article with the strict proviso that no changes or edits are made and the original work is properly cited (including links to both the formal publication through the relevant DOI and the license). See: https://creativecommons.org/licenses/by-nc-nd/4.0/.

\section{References}

1. Parihar VK, Acharya MM, Roa DE, et al. Defining functional changes in the brain caused by targeted stereotaxic radiosurgery. Transl Cancer Res 2014;3:124-37.

(Science Editor: Brad Li, TCR, tcr@amepc.org)
Cite this article as: $\mathrm{Li} \mathrm{B}$. Charles L. Limoli: the study of brain irradiation is a labor of love. Transl Cancer Res 2018;7(Suppl 7):S813-S815. doi: 10.21037/tcr.2018.07.10 